\title{
Independent Risk Factors for Mortality in Patients with Chronic Obstructive Pulmonary Disease Who Undergo Comprehensive Cardiac Evaluations
}

\author{
Young-Hwan Ahn ${ }^{a}$ Keu Sung Lee ${ }^{a}$ Joo Hun Park ${ }^{a}$ Jin-Hee Jung ${ }^{a}$ \\ Miyeon Lee ${ }^{a}$ Yun-Jung Jung ${ }^{a}$ Wou Young Chung ${ }^{a}$ Seungsoo Sheen ${ }^{a}$ \\ Kwang Joo Park ${ }^{a}$ Dae Jung Kim ${ }^{c}$ Dae Ryoung Kang ${ }^{d}$ Jeong-Dong Lee ${ }^{d}$ \\ Soojee Yoon ${ }^{\mathrm{e}}$ Xiong Jie Jin ${ }^{\mathrm{b}}$ Hyoung-Mo Yang ${ }^{\mathrm{b}}$ Hong-Seok Lim ${ }^{\mathrm{b}}$ \\ Jin Sun Park ${ }^{b}$ Joon-Han Shin ${ }^{b}$ Seung-Jea Tahk ${ }^{b}$ \\ Departments of a Pulmonary and Critical Care Medicine, ${ }^{b}$ Cardiology and ${ }^{c}$ Endocrinology and Metabolism, and \\ ${ }^{d}$ Office of Biostatistics, Department of Medical Humanities and Social Medicine, Ajou University School of Medicine, \\ Suwon, and ${ }^{\mathrm{e}}$ Department of Internal Medicine, Wooridul Hospital, Seoul, Republic of Korea
}

For editorial comment see p. 187

\section{Key Words}

Chronic obstructive pulmonary disease $\cdot$ Hemoglobin

levels $\cdot$ Left heart failure $\cdot$ Mortality

\begin{abstract}
Background: Cardiovascular disease is the most common cause of death in chronic obstructive pulmonary disease (COPD). However, the impact of cardiovascular comorbidities on the prognosis of COPD is not well known. Objectives: This study was performed to investigate the effects of cardiovascular comorbidities on the prognosis of COPD. Methods: We enlisted 229 patients with COPD who underwent comprehensive cardiac evaluations including coronary angiography and echocardiography at Ajou University Hospital between January 2000 and December 2012. Survival analyses were performed in this retrospective cohort. Results: Kaplan-Meier analyses showed that COPD patients without left heart failure (mean survival $=12.5 \pm 0.7$ years) survived longer than COPD patients with left heart failure (mean survival $=6.7 \pm 1.4$ years; $p=0.003$ ), and the survival period of
\end{abstract}

nonanemic COPD patients (mean survival $=13.8 \pm 0.8$ years) was longer than that of anemic COPD patients (mean survival $=8.3 \pm 0.8$ years; $p<0.001$ ). The survival period in COPD with coronary artery disease $(C A D$; mean survival $=11.37 \pm$ 0.64 years) was not different from that in COPD without CAD (mean survival $=11.98 \pm 0.98$ years; $p=0.703$ ). According to a multivariate Cox regression model, a lower hemoglobin level, a lower left ventricular ejection fraction, and the forced expiratory volume in $1 \mathrm{~s}\left(\mathrm{FEV}_{1}\right)$ were independently associated with higher mortality in the total COPD group $(p<0.05)$. Conclusions: Hemoglobin levels and left ventricular ejection fraction along with a lower $\mathrm{FEV}_{1}$ were identified as independent risk factors for mortality in COPD patients who underwent comprehensive cardiac evaluations, suggesting that multidisciplinary approaches are required in the care of COPD.

(c) 2015 S. Karger AG, Basel

Y.-H. Ahn and K.S. Lee contributed equally to this paper. This work has not been published elsewhere previously.

\section{KARGER 125}

(c) 2015 S. Karger AG, Basel

$0025-7931 / 15 / 0903-0199 \$ 39.50 / 0$

E-Mail karger@karger.com

www.karger.com/res
Joo Hun Park, MD

Department of Pulmonary and Critical Care Medicine

Ajou University School of Medicine, Worldcup Road 164, San 5

Wonchon-dong, Yeongtong-gu, Suwon, Gyeonggi-do 443-721 (Republic of Korea)

E-Mail jhpamc@hanmail.net 


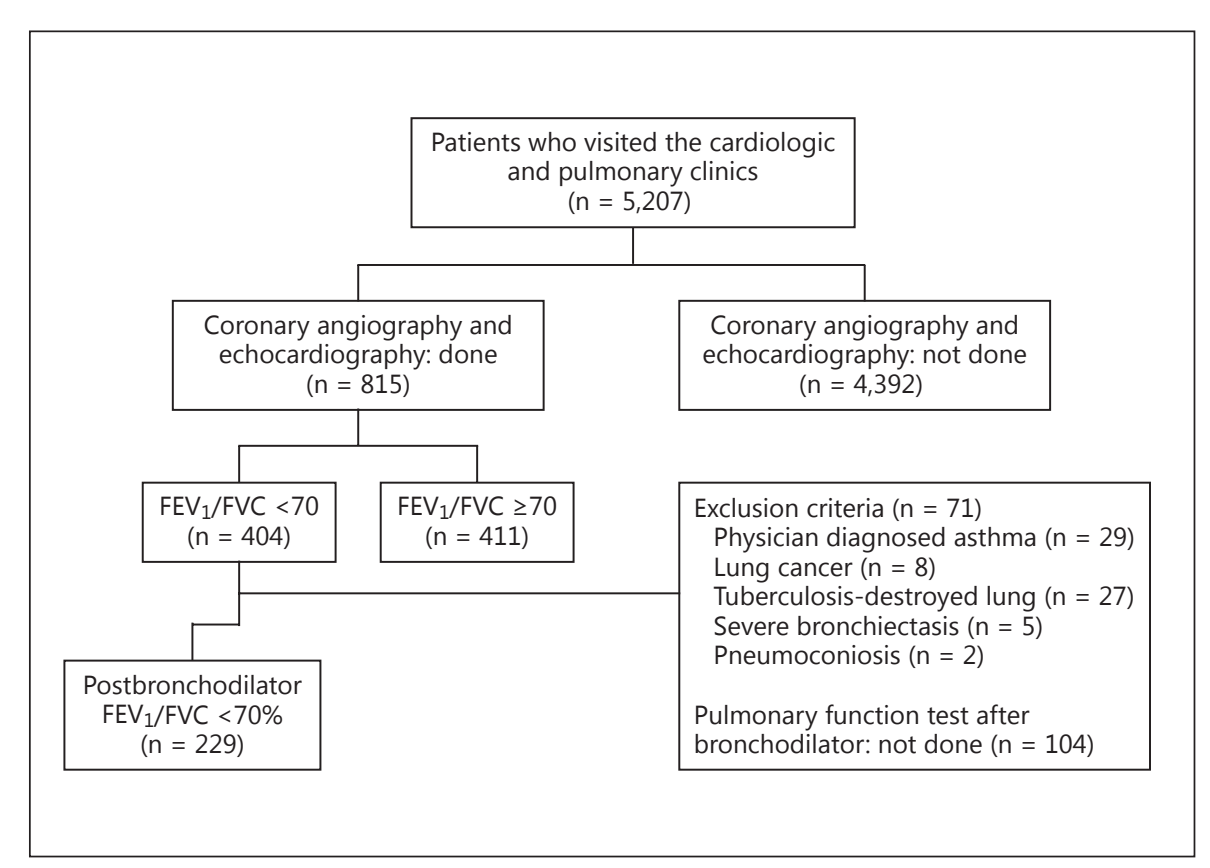

Fig. 1. Flow diagram of the subject enrollment.

\section{Introduction}

Chronic obstructive pulmonary disease (COPD) is an increasing cause of morbidity and mortality worldwide [1]. COPD is now recognized not as a single disease but as a syndrome with multiple phenotypes accompanied by many comorbidities [2,3]. Cardiovascular comorbidities are the main causes of mortality in COPD, and atherosclerosis may occur in COPD regardless of the smoking history [4-6]. Among many cardiovascular comorbidities, heart failure and coronary artery disease (CAD), which often coexist with COPD, present clinicians with diagnostic and therapeutic challenges [7-8].

However, the prognostic impact of each cardiovascular comorbidity is difficult to evaluate because cardiological evaluations, including echocardiography and data coronary angiography, are extremely difficult to obtain in COPD $[9,10]$. To date, few reports have evaluated the subset of patients with COPD who underwent cardiac tests, including coronary angiography and echocardiography, although some studies have investigated the clinical course of COPD with CAD [11-12].

Thus, this study was performed to investigate the effect of cardiovascular comorbidities on the prognosis in patients with COPD who underwent comprehensive cardiological evaluations including diagnostic coronary angiography and echocardiography.

\section{Methods}

Subjects

We retrospectively reviewed 5,207 patients who, on an outpatient basis, visited the pulmonary clinic and the cardiologic clinic at Ajou University Hospital (a university-affiliated, 1,000-bed tertiary referral center in Suwon, Republic of Korea) at the same time, namely between January 2000 and December 2012. Of those, we enlisted 229 patients with COPD who had undergone comprehensive cardiac evaluations including coronary angiography and echocardiography performed by cardiologists. As shown in figure 1,27 patients with tuberculous-destroyed lung, 5 with severe bronchiectasis, 2 with pneumoconiosis, 29 with physician-diagnosed asthma, and 8 with lung cancer were excluded from our study.

All clinical and laboratory parameters were obtained within 1 month before cardiac evaluations. The clinical history, comorbidities, demographics, medication history, laboratory findings, and radiological findings were acquired from medical records. The survival period was calculated from the time of the cardiac evaluations. The mean observation period was $6.48 \pm 4.09$ years. Survival status was obtained from a telephone interview, medical records, or Statistics Korea (kostat.go.kr).

\section{Diagnosis}

The diagnosis of COPD was determined by clinician's judgment with the following two criteria: the postbronchodilator ratio of the forced expiratory volume in $1 \mathrm{~s}\left(\mathrm{FEV}_{1}\right)$ to forced vital capacity (FVC) $<70 \%$ and no or minimal abnormality on chest radiography [1]. The interpretation of the coronary angiography was made by 2 cardiologists who were blinded to the clinical characteristics of the patients.

CAD was defined as $>50 \%$ stenosis of at least 1 major coronary artery. Left heart failure was defined as $\leq 40 \%$ ejection fraction according to echocardiographic findings reported by cardiologists [13]. 


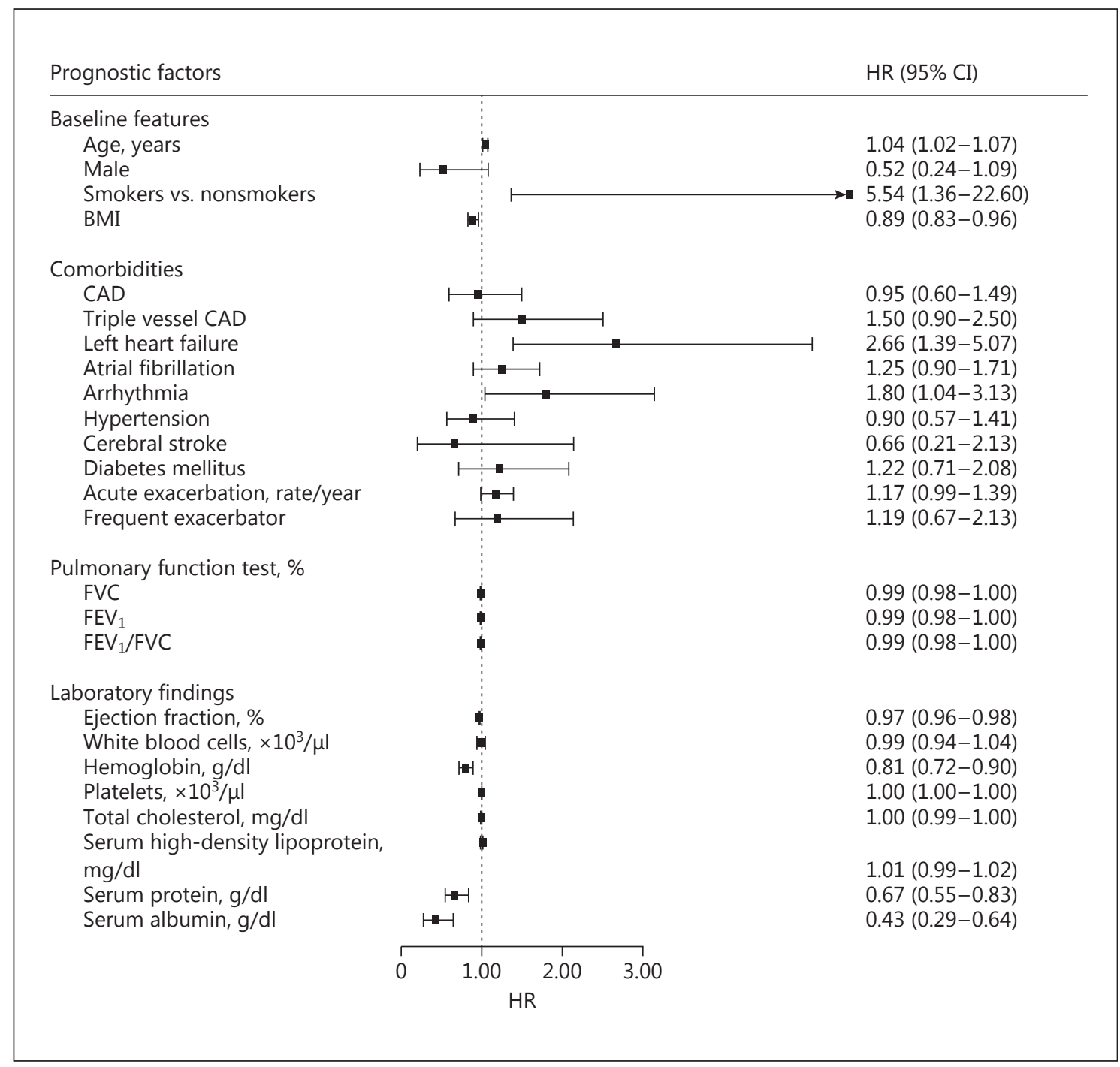

Fig. 2. Prognostic factors for survival in COPD patients using a univariate Cox model.

Anemia was determined by the reference values of hemoglobin: $<12 \mathrm{~g} / \mathrm{dl}$ for women and $<13 \mathrm{~g} / \mathrm{dl}$ for men [14].

Data on the duration and amount of cigarette smoking were obtained, and an ex-smoker was defined as a subject who had not smoked for at least 1 year. Body mass index (BMI) was calculated as the body weight divided by the height squared $\left(\mathrm{kg} / \mathrm{m}^{2}\right)$.

Acute exacerbation was defined according to the GOLD document [1]. If the patient's condition worsened, and a course of oral corticosteroid and antibiotics was indicated based on the clinician's judgment, exacerbation was defined as moderate. If hospitalization was required, at the discretion of the clinician, exacerbation was considered severe. We included only moderate and severe exacerbations in the exacerbation group of COPD, as in other studies $[15,16]$. Spirometry (Elite-DX or CPFS; Medgraphics, Saint Paul, Minn., USA) was performed according to the American Thoracic Society guidelines [17].

Independent Risk Factors for COPD Mortality

\section{Statistical Analysis}

The SPSS software (version 22; SPSS Inc., Chicago, Ill., USA) and ' $\mathrm{R}$ ' (version 3.1.1) were used for all analyses. The $\chi^{2}$ test or Fisher's exact test were applied for categorical data, and Student's $t$ test was used for continuous data. We determined the 95\% confidence interval (CI) of each variable from the mean and standard deviation. A p value $<0.05$ was deemed to indicate statistical significance.

We first carried out univariate Cox regression analyses to identify significant predictors influencing overall survival. For the multivariate analysis by the Cox regression model, we selected variables by the significance of the hazard ratio (HR) in the univariate Cox regression model, and putative factors deemed to influence the prognosis of COPD.

We generated a forest plot representing the HRs and their corresponding CIs using ' $\mathrm{R}$ ' with the survival library, ggplot2 library, 
Table 1. Baseline characteristics of the 229 COPD patients

\begin{tabular}{lc}
\hline Age, years & $69.2 \pm 9.2$ \\
Male, $\mathrm{n}$ & $202(88.2)$ \\
Smoking (yes/not anymore/never), \% & $45.8 / 41.4 / 12.8$ \\
Smoking, pack-years & $45.3 \pm 23.9$ \\
BMI & $23.4 \pm 3.2$ \\
Pulmonary function (\% predicted) after & \\
$\quad$ bronchodilator challenge & \\
$\quad$ FVC & $87.2 \pm 13.8$ \\
$\quad$ FEV & $63.7 \pm 18.6$ \\
FEV $/$ FVC & $54.6 \pm 10.9$ \\
CAD & $136(59.4)$ \\
Atrial fibrillation & $24(10.5)$ \\
Arrhythmia & $33(14.5)$ \\
Ejection fraction, \% & $59.3 \pm 13.8$ \\
Anemia & $73(31.9)$ \\
Complete blood count & \\
$\quad$ White blood cells, $\times 10^{3} / \mu l$ & $8.4 \pm 4.1$ \\
$\quad$ Hemoglobin, $/ \mathrm{dl}$ & $13.0 \pm 2.0$ \\
Platelets, $\times 10^{3} / \mu l$ & $232.6 \pm 69.9$ \\
Total cholesterol, mg/dl & $164.6 \pm 40.65$ \\
HDL cholesterol, mg/dl & $45.8 \pm 14.2$ \\
Comorbidities & \\
$\quad$ Diabetes mellitus & $46(20.1)$ \\
Hypertension & $132(57.6)$ \\
Left heart failure & $21(9.7)$ \\
Cerebral stroke & $11(4.9)$ \\
Acute exacerbation per year & $0.55 \pm 1.04$ \\
Frequent exacerbator & $37(16.2)$ \\
\hline
\end{tabular}

Variables are expressed as means \pm SD or $n(\%)$, unless otherwise indicated. HDL = High-density lipoprotein.

and metafor library to extract a set of meaningful variables in the univariate survival analysis (fig. 2) [18].

Ethics Statement

The present study was approved by the Institutional Review Board of Ajou University Hospital (approval No. MEDMDB-13-076).

\section{Results}

Baseline Characteristics of the Patients with COPD

The mean age of the participants was $69.2 \pm 9.2$ years, and $88.2 \%$ of the cohort were males. In the cohort, CAD was diagnosed in $59.4 \%$, atrial fibrillation was detected in $10.5 \%$, and anemia was found in $31.9 \%$ of the patients (table 1). In 136 patients with COPD and CAD, 73.5\% (100 patients) were treated with percutaneous coronary intervention, $11.8 \%$ (16 patients) underwent coronary artery bypass graft, and $92.6 \%$ (126 patients) received stan-
Table 2. Prognostic factors for the mortality in the total COPD group by multivariate Cox regression analysis

\begin{tabular}{lll}
\hline & HR $(95 \% \mathrm{CI})$ & $\begin{array}{l}\mathrm{p} \\
\text { value }\end{array}$ \\
\hline Age, years & $1.02(0.99-1.05)$ & 0.239 \\
Male & $1.48(0.56-3.93)$ & 0.427 \\
Smoking & $1.10(0.42-2.89)$ & 0.842 \\
BMI & $0.97(0.89-1.05)$ & 0.476 \\
Hemoglobin, g/dl & $0.81(0.72-0.92)$ & 0.001 \\
CAD & $0.85(0.53-1.37)$ & 0.512 \\
Left ventricular ejection fraction & $0.98(0.96-0.99)$ & 0.002 \\
FEV & $0.98(0.97-1.00)$ & 0.012 \\
\hline Harrell's C statistics & $0.728(\mathrm{SE}=0.037)$ \\
\hline
\end{tabular}

$\mathrm{SE}=$ Standard error

dard medical treatment, including aspirin, statin, and clopidogrel for treating CAD.

Among the 78 patients with COPD who died during the observation period, mortality was most frequently due to heart failure (16 patients, $20.5 \%$ ). Other causes were respiratory failure due to acute exacerbation of COPD (11 patients, 14.1\%), pneumonia (11 patients, $14.1 \%)$, lung cancer (6 patients, $7.7 \%$ ), cancers other than lung cancer ( 9 patients, $11.5 \%$ ), septic shock ( 3 patients, $3.8 \%)$, cerebrovascular disease (11 patients, $14.1 \%$ ), renal failure (3 patients, $3.8 \%$ ), pulmonary embolism (2 patients, $2.6 \%$ ), and 6 unknown causes (7.7\%). Only allcause mortality was used for the survival analysis because the cause of death was not known in some cases.

\section{Survival Analyses by the Kaplan-Meier Method}

Kaplan-Meier analyses showed that COPD without left heart failure (mean survival $=12.48 \pm 0.69$ years) survived longer than COPD with left heart failure (mean survival $=6.68 \pm 1.40$ years; $p=0.003)$, and the survival period of non-anemic COPD (mean survival $=13.82 \pm 0.76$ years) was longer than anemic COPD (mean survival = $8.29 \pm 0.77$ years; $p<0.001$; fig. 3 ). The survival period of COPD without atrial fibrillation (mean survival $=12.50$ \pm 0.67 years) showed no significant difference compared to the survival period of COPD with atrial fibrillation ( mean survival $=8.74 \pm 1.31$ years; $\mathrm{p}=0.127$; fig. 3 ). However, the survival period of COPD with coronary artery disease (mean survival $=11.37 \pm 0.64$ years) was not different from that of COPD without coronary artery disease (mean survival $=11.98 \pm 0.98$ years; $\mathrm{p}=0.703$ ), although COPD with triple-vessel coronary artery disease 


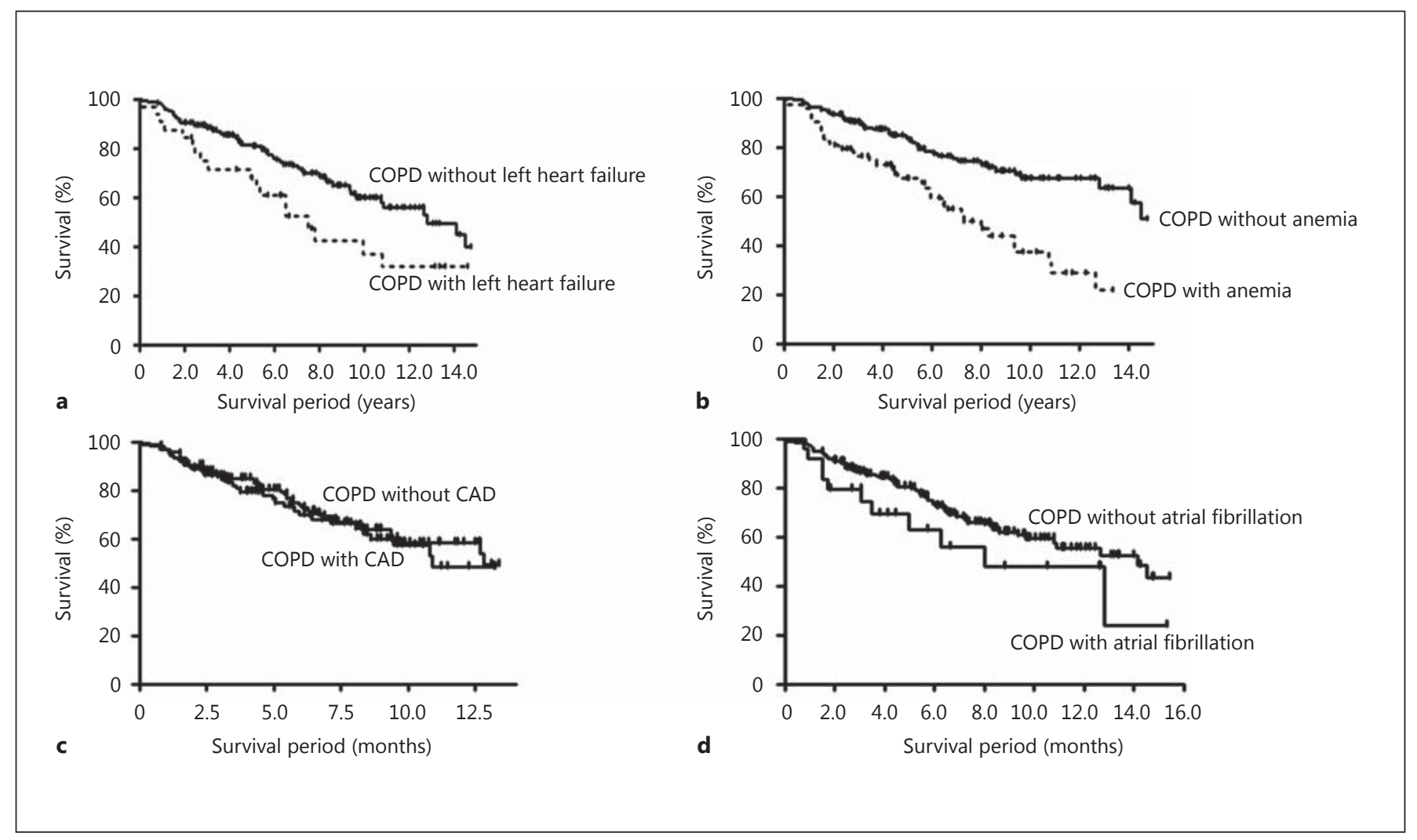

Fig. 3. Survival analysis of patients with COPD by the KaplanMeier method. a Comparison between COPD without left heart failure (mean survival $=12.48 \pm 0.69$ years) and COPD with left heart failure (mean survival $=6.68 \pm 1.40$ years; $p=0.003$ ). $\mathbf{b}$ Comparison between nonanemic COPD (mean survival $=13.82 \pm 0.76$ years) and anemic COPD (mean survival $=8.29 \pm 0.77$ years; $p<$

(mean survival $=8.61 \pm 0.82$ years) survived longer than COPD without triple-vessel disease (mean survival = $12.91 \pm 0.70$ years; $\mathrm{p}=0.049$ ).

\section{Survival Analysis by the Cox Regression Method}

According to the univariate Cox model, age, smoking, BMI, left heart failure, arrhythmia, anemia, serum hemoglobin level, FVC, $\mathrm{FEV}_{1}, \mathrm{FEV}_{1} / \mathrm{FVC}$, serum protein level, and serum albumin level were significant parameters of all-cause mortality (fig. 2).

Multivariate Cox regression analysis showed that a lower hemoglobin level (HR 0.81 per $1 \mathrm{~g} / \mathrm{dl}, 95 \% \mathrm{CI}=$ $0.72-0.92, \mathrm{p}=0.001)$, a lower left ventricular ejection fraction (HR 0.98 per $1 \%$ increase of ejection fraction, 95\% CI $=0.96-0.99, \mathrm{p}=0.002)$, and $\mathrm{FEV}_{1}$ (HR 0.98 per $1 \%$ increase of $\mathrm{FEV}_{1}, 95 \% \mathrm{CI}=0.97-1.00, \mathrm{p}=0.012$ ) were independent risk factors for higher mortality in total COPD patients (table 2).

Independent Risk Factors for COPD Mortality
0.001). $\mathbf{c}$ Comparison between COPD with CAD (mean survival = $11.37 \pm 0.64$ years) and COPD without CAD (mean survival 11.98 \pm 0.98 years; $\mathrm{p}=0.703)$. $\mathbf{d}$ Comparison between COPD with atrial fibrillation (mean survival $=8.74 \pm 1.31$ years) and COPD without atrial fibrillation (mean survival $=12.50 \pm 0.67$ years; $\mathrm{p}=0.127$ ).

\section{Discussion}

The aim of this study was to investigate the influence of cardiovascular comorbidities on the prognosis of COPD patients. Our study demonstrated that a lower serum hemoglobin level and left heart failure along with a lower $\mathrm{FEV}_{1}$ were independent risk factors for mortality in COPD patients.

According to the "Towards a Revolution in COPD Health' (TORCH) trial [5], 27\% of the deaths that occurred during the observation period were due to cardiovascular causes. However, they did not specify which cardiovascular mortalities contributed what percentage to the mortality in their cohort [5]. One study reported that mortality for COPD patients with CAD reached $21 \%$ at the 3-year follow-up in a study of 4,528 patients [19].

However, the true impact of cardiac comorbidities on the survival in COPD was not well explained because the 
occult CAD in COPD, which should be confirmed by coronary angiography, was not identified in most studies $[19,20]$. Occult CAD has been reported to be found in $59 \%$ of the COPD patients [9].

We are of the opinion that our study evaluated the influence of cardiac comorbidities on the prognosis of COPD patients better than other studies because comprehensive cardiac evaluations including echocardiography and an electrocardiogram were analyzed, and occult CAD confirmed by angiography was not included in the group of COPD without CAD.

We discuss here some noteworthy findings. First, our study found that left heart failure, among all cardiac comorbidities, was the prognostic factor independently associated with the highest mortality of COPD patients in multivariate Cox regression analysis, in addition to the well-known risk factor $\mathrm{FEV}_{1}$. However, the presence of CAD was not a risk factor for mortality, though COPD patients with triple-vessel CAD had a shorter survival period than COPD patients without triple-vessel CAD.

There are few data yet suggesting that a decreased left heart function, marked by a lower ejection fraction, is independently associated with mortality in COPD. One recent report suggested that in a cohort of patients hospitalized for acute exacerbation of COPD, previously recorded congestive heart failure is an independent predictor of mortality within the first year after admission [21]. It was currently reported that left ventricular ejection fraction was not associated with percent emphysema and airflow obstruction, although COPD and a reduced $\mathrm{FEV}_{1}$ are markers for cardiovascular mortality $[19,22,23]$.

A possible explanation for why $\mathrm{CAD}$ was not associated with survival in our study is that the COPD patients with CAD in our cohort were treated with the best possible care at the cardiology clinic. Out of the COPD patients with $\mathrm{CAD}, 73.5 \%$ were treated with percutaneous coronary intervention, $11.8 \%$ underwent coronary artery bypass graft, and $92.6 \%$ received standard medical treatment including aspirin and a statin. Thus, our survival data cannot be generalized until they are validated in future studies because our cohort does not represent the general COPD population and this cohort consisted of COPD patients who visited the cardiology clinic. Furthermore, additional studies with bigger cohorts and/or a randomized controlled design are required as to the effect of CAD with multi-vessel involvement on the long-term prognosis of COPD patients because our data showed that COPD patients with triple-vessel involvement of CAD survived shorter, although this finding was not proven in the multivariate analysis. Another limitation of our study is that we did not determine laboratory markers of heart failure to support the link between heart failure and mortality in COPD.

Second, our data showed that a low serum hemoglobin level was a strong independent factor associated with survival in our COPD cohort.

Anemia was detected in $31.9 \%$ of our cohort, which is higher than the $12.6 \%$ of the men and $8.2 \%$ of the women in a severe COPD cohort receiving long-term oxygen therapy reported by Chambellan et al. [24] and the 17\% in the report by Cote et al. [25]. However, the prevalence in our cohort is a little lower than that in a recent report where $43.9 \%$ were found to be anemic on admission due to COPD with acute exacerbation [26].

In the cohort of 207 patients reported by Celli et al. [27] to evaluate the BODE prognostic index with 1-year mortality, hematocrit was significantly higher in the patients who survived compared with those who died. Previous reports showed that the correction of anemia can decrease dyspnea, the work of breathing, and minute ventilation in COPD [26, 28].

Our findings are further supported by the evidence that hematocrit was an independent predictor of survival, the hospital admission rate, and the duration of hospitalization in COPD patients with long-term oxygen therapy [24]. It has recently been reported that even in stable COPD outpatients, anemia is independently associated with survival [29].

Anemia can be manifested as one of the comorbidities developing due to chronic inflammation in COPD and low-grade systemic inflammation, which can lead to atherosclerosis and increases the risk of major comorbidities in COPD independent of smoking [30-32]. Further studies are needed about the effects of anemia correction on the long-term outcomes in COPD.

Our study has several limitations. First, because the cohort of the present study was enrolled at a single center where cardiac evaluations are performed, selection bias could be present. Second, clinical assessments by the COPD Assessment Test, Medical Research Council Dyspnea Scale, and St. George Respiratory Questionnaire were not obtained at the point of initial enrollment because of the study's retrospective design. Third, our study did not precisely measure the true prevalence of CAD in COPD because only COPD patients who visited the cardiology clinic for evaluating cardiac disorders were enrolled.

In conclusion, our study identified a lower left ventricular ejection fraction and lower hemoglobin levels along with a lower $\mathrm{FEV}_{1}$ as independent risk factors for mortality in COPD patients, suggesting that multidisciplinary approaches are required in the care of COPD patients. 


\section{Acknowledgment}

This study was supported by a 2013 grant from Ajou University Graduate School of Medicine, Suwon, Republic of Korea.

\section{Financial Disclosure and Conflicts of Interest}

All authors have no financial relationship with a commercial entity that has an interest in the subject of this paper.

\section{References}

${ }_{1}$ Vestbo J, Hurd SS, Agustí AG, Jones PW, Vogelmeier C, Anzueto A, Barnes PJ, Fabbri LM, Martinez FJ, Nishimura M, Stockley RA, Sin $\mathrm{DD}$, Rodriguez-Roisin R: Global strategy for the diagnosis, management, and prevention of chronic obstructive pulmonary disease: GOLD executive summary. Am J Respir Crit Care Med 2013;187:347-365.

- 2 Han MK, Agusti A, Calverley PM, Celli BR, Criner G, Curtis JL, Fabbri LM, Goldin JG, Jones PW, Macnee W, Make BJ, Rabe KF, Rennard SI, Sciurba FC, Silverman EK, Vestbo J, Washko GR, Wouters EF, Martinez FJ: Chronic obstructive pulmonary disease phenotypes: the future of COPD. Am J Respir Crit Care Med 2010;182: 598-604.

-3 Vanfleteren LE, Spruit MA, Groenen M, Gaffron S, van Empel VP, Bruijnzeel PL, Rutten EP, Op 't Roodt J, Wouters EF, Franssen FM: Clusters of comorbidities based on validated objective measurements and systemic inflammation in patients with chronic obstructive pulmonary disease. Am J Respir Crit Care Med 2013;187: 728-735.

-4 McAllister DA, Maclay JD, Mills NL, Mair G, Miller J, Anderson D, Newby DE, Murchison JT, Macnee W: Arterial stiffness is independently associated with emphysema severity in patients with chronic obstructive pulmonary disease. Am J Respir Crit Care Med 2007;176: 1208-1214.

-5 Calverley PM, Anderson JA, Celli B, Ferguson GT, Jenkins C, Jones PW, Yates JC, Vestbo J; TORCH Investigators: Salmeterol and fluticasone propionate and survival in chronic obstructive pulmonary disease. N Engl J Med 2007;356:775-789.

6 6 Preiss D, Thomas LE, Sun JL, Haffner SM, Holman RR, Standl E, Leiter LA, Mazzone T, Rutten GE, Tognoni G, Martinez FA, Chiang FT, Califf RM, McMurray JJ: Predictors of cardiovascular events in a contemporary population with impaired glucose tolerance: an observational analysis of the nateglinide and valsartan in impaired glucose tolerance outcomes research (NAVIGATOR) trial. BMJ Open 2012;2:pii:e001925.

7 Le Jemtel TH, Padeletti M, Jelic S: Diagnostic and therapeutic challenges in patients with coexistent chronic obstructive pulmonary disease and chronic heart failure. J Am Coll Cardiology 2007;49:171-180.

8 de Miguel Diez J, Chancafe Morgan J, Jimenez Garcia R: The association between COPD and heart failure risk: a review. Int $J$ Chron Obstruct Pulmon Dis 2013;8:305-312.

9 Reed RM, Eberlein M, Girgis RE, Hashmi S, Iacono A, Jones S, Netzer G, Scharf S: Coronary artery disease is under-diagnosed and undertreated in advanced lung disease. Am J Med 2012;125:1228.e13-1228.e22.
10 Brekke PH, Omland T, Smith P, Soyseth V: Underdiagnosis of myocardial infarction in COPD - Cardiac Infarction Injury Score (CIIS) in patients hospitalised for COPD exacerbation. Respir Med 2008;102:1243-1247.

11 Williams MC, Murchison JT, Edwards LD, Agustí A, Bakke P, Calverley PM, Celli B, Coxson HO, Crim C, Lomas DA, Miller BE, Rennard S, Silverman EK, Tal-Singer R, Vestbo J, Wouters E, Yates JC, van Beek EJ, Newby DE, MacNee W; Evaluation of COPD Longitudinally to Identify Predictive Surrogate Endpoints (ECLIPSE) Investigators: Coronary artery calcification is increased in patients with COPD and associated with increased morbidity and mortality. Thorax 2014;69:718-723.

12 Sidney S, Sorel M, Quesenberry CP Jr, DeLuise $\mathrm{C}$, Lanes S, Eisner MD: COPD and incident cardiovascular disease hospitalizations and mortality: Kaiser Permanente Medical Care Program. Chest 2005;128:2068-2075.

13 Bhatia RS, Tu JV, Lee DS, Austin PC, Fang J, Haouzi A, Gong Y, Liu PP: Outcome of heart failure with preserved ejection fraction in a population-based study. N Engl J Med 2006;355: 260-269.

14 Beutler E, Waalen J: The definition of anemia: what is the lower limit of normal of the blood hemoglobin concentration? Blood 2006;107: 1747-1750.

15 Wouters EF, Postma DS, Fokkens B, Hop WC, Prins J, Kuipers AF, Pasma HR, Hensing CA, Creutzberg EC; COSMIC (COPD and Seretide: a Multi-Center Intervention and Characterization) Study Group: Withdrawal of fluticasone propionate from combined salmeterol/fluticasone treatment in patients with COPD causes immediate and sustained disease deterioration: a randomised controlled trial. Thorax 2005;60: 480-487.

16 Oh YM, Sheen SS, Park JH, Jin UR, Yoo JW, Seo JB, Yoo KH, Lee JH, Kim TH, Lim SY, Yoon HI, Lee JS, Lee SD: Emphysematous phenotype is an independent predictor for frequent exacerbation of COPD. Int J Tuberc Lung Dis 2014;18: 1407-1414.

17 Standardization of Spirometry, 1994 Update. American Thoracic Society. Am J Respir Crit Care Med 1995; 152:1107-1136.

18 Lewis S, Clarke M: Forest plots: trying to see the wood and the trees. BMJ 2001;322:14791480.

19 Berger JS, Sanborn TA, Sherman W, Brown DL: Effect of chronic obstructive pulmonary disease on survival of patients with coronary heart disease having percutaneous coronary intervention. Am J Cardiol 2004;94:649-651.

20 Sin DD, Man SF: Why are patients with chronic obstructive pulmonary disease at increased risk of cardiovascular diseases? The potential role of systemic inflammation in chronic obstructive pulmonary disease. Circulation 2003; 107:1514-1519.

21 Slenter RH1, Sprooten RT, Kotz D, Wesseling G, Wouters EF, Rohde GG: Predictors of 1-year mortality at hospital admission for acute exacerbations of chronic obstructive pulmonary disease. Respiration 2013;85:15-26.

22 Sin DD, Wu L, Man SF: The relationship between reduced lung function and cardiovascular mortality: a population-based study and a systematic review of the literature. Chest 2005; 127:1952-1959.

-23 Barr RG, Bluemke DA, Ahmed FS, Carr JJ, Enright PL, Hoffman EA, Jiang R, Kawut SM, Kronmal RA, Lima JA, Shahar E, Smith LJ, Watson KE: Percent emphysema, airflow obstruction, and impaired left ventricular filling. N Engl J Med 2010;362:217-227.

-24 Chambellan A, Chailleux E, Similowski T: Prognostic value of the hematocrit in patients with severe COPD receiving long-term oxygen therapy. Chest 2005;128:1201-1208.

25 Cote C, Zilberberg MD, Mody SH, Dordelly LJ, Celli B: Haemoglobin level and its clinical impact in a cohort of patients with COPD. Eur Respir J 2007;29:923-929.

26 Silverberg DS, Mor R, Weu MT, Schwartz D, Schwartz IF, Chernin G: Anemia and iron deficiency in COPD patients: prevalence and the effects of correction of the anemia with erythropoiesis stimulating agents and intravenous iron. BMC Pulm Med 2014;14:24.

27 Celli BR, Cote CG, Marin JM, Casanova C, Montes de Oca M, Mendez RA, Pinto Plata V, Cabral HJ: The body-mass index, airflow obstruction, dyspnea, and exercise capacity index in chronic obstructive pulmonary disease. $\mathrm{N}$ Engl J Med 2004;350:1005-1012.

28 Schonhofer B, Wenzel M, Geibel M, Köhler D: Blood transfusion and lung function in chronically anemic patients with severe chronic obstructive pulmonary disease. Crit Care Med 1998;26:1824-1828.

29 Boutou AK, Karrar S, Hopkinson NS, Polkey MI: Anemia of chronic disease in chronic obstructive pulmonary disease: a case-control study of cardiopulmonary exercise responses. Respiration 2013;85:126-131.

30 Thomsen M, Dahl M, Lange P, Vestbo J, Nordestgaard BG: Inflammatory biomarkers and comorbidities in chronic obstructive pulmonary disease. Am J Respir Crit Care Med 2012; 186:982-988.

31 Ross R: Atherosclerosis - an inflammatory disease. N Engl J Med 1999;340:115-126.

-32 John M, Hoernig S, Doehner W, Okonko DD, Witt C, Anker SD: Anemia and inflammation in COPD. Chest 2005;127:825-829. 